Article

\title{
Mechanical and Thermal Analyses of Metal-PLA Components Fabricated by Metal Material Extrusion
}

\author{
Mahdi Mohammadizadeh ${ }^{1}$, Hao Lu ${ }^{2}$, Ismail Fidan ${ }^{3, *}{ }^{\mathbb{C}}$, Khalid Tantawi ${ }^{4}\left(\mathbb{D}\right.$, Ankit Gupta ${ }^{2}$, \\ Seymur Hasanov ${ }^{2}$, Zhicheng Zhang ${ }^{2}$, Frank Alifui-Segbaya ${ }^{5}$ and Allan Rennie ${ }^{6}$ \\ 1 Center for Manufacturing Research, College of Engineering, Tennessee Tech University, \\ Cookeville, TN 38505, USA; mmohammad42@students.tntech.edu \\ 2 Department of Mechanical Engineering, College of Engineering, Tennessee Tech University, \\ Cookeville, TN 38505, USA; hlu42@students.tntech.edu (H.L.); agupta42@students.tntech.edu (A.G.); \\ shasanov42@students.tntech.edu (S.H.); zzhang44@students.tntech.edu (Z.Z.) \\ 3 Department of Manufacturing and Engineering Technology, College of Engineering, \\ Tennessee Tech University, Cookeville, TN 38505, USA \\ 4 Department of Engineering Technology and Management, College of Engineering and Computer Science, \\ University of Tennessee at Chattanooga, Chattanooga, TN 37403, USA; Khalid-Tantawi@utc.edu \\ 5 School of Dentistry and Oral Health, Griffith Health, Griffith University, Gold Coast Campus, \\ Southport, QLD 4222, Australia; f.alifui-segbaya@griffith.edu.au \\ 6 Department of Engineering, Faculty of Science and Technology, Lancaster University, \\ Lancaster LA1 4YR, UK; a.rennie@lancaster.ac.uk \\ * Correspondence: ifidan@tntech.edu; Tel.: +1-931-372-6298
}

Received: 31 July 2020; Accepted: 21 August 2020; Published: 24 August 2020

check for updates

\begin{abstract}
Metal additive manufacturing (AM) has gained much attention in recent years due to its advantages including geometric freedom and design complexity, appropriate for a wide range of potential industrial applications. However, conventional metal AM methods have high-cost barriers due to the initial cost of the capital equipment, support, and maintenance, etc. This study presents a low-cost metal material extrusion technology as a prospective alternative to the production of metallic parts in additive manufacturing. The filaments used consist of copper, bronze, stainless steel, high carbon iron, and aluminum powders in a polylactic acid matrix. Using the proposed fabrication technology, test specimens were built by extruding metal/polymer composite filaments, which were then sintered in an open-air furnace to produce solid metallic parts. In this research, the mechanical and thermal properties of the built parts are examined using tensile tests, thermogravimetric, thermomechanical and microstructural analysis.
\end{abstract}

Keywords: metal additive manufacturing; sintering; tensile; mechanical analysis; metal material extrusion

\section{Introduction}

Additive manufacturing (AM) is a novel method of manufacturing parts directly from computer models using a layer-by-layer material deposition process. In recent years, AM technology has had an increasing rate of usage in different industries [1]. Due to the wide range of applications, much research has been undertaken to investigate the properties of AM parts for practical uses [2]. In general, AM exhibits many advantages, including design flexibility, reduced energy consumption and shortened manufacturing times compared with traditional manufacturing methods $[3,4]$.

AM systems are categorized into four main groups of metals [4], polymers [5,6], ceramics [7], and composite systems [8-11]. In the last two decades, metal AM has emerged as an important commercial manufacturing technology [12] with a wide range of applications in the automotive, 
aerospace, oil, and gas, and marine industries, and the technology has attracted significant attention $[3,13]$. However, the high energy source that fuses or melts the metal powder to produce parts layer-by-layer [14,15] in metal AM processes, such as selective laser sintering (SLS), selective laser melting (SLM), and direct metal deposition (DMD), warrants the need for increased electrical energy use, specialist environments (e.g., inert gases) and health and safety considerations for component extraction post-fabrication. Apart from this, sophisticated machines, equipment, and facilities are required for the manufacturing and post-processing of end-use parts [16]. Furthermore, the high cost associated with acquiring and operating metal AM systems makes them less financially viable for individuals and small organizations [17]. In this regard, metal material extrusion (MME) technology comes to the fore as a prospective alternative to reduce cost and simplify the production of additively manufactured metallic parts.

MME is a material extrusion process reliant on the popular fused deposition modeling (FDM) [18]. In MME, physical parts are built with composite filaments consisting of metal powders in a polymer matrix. The parts subsequently undergo secondary debonding and sintering in a heated furnace to form almost a $100 \%$ solid metal [19]. It is worth stating that the printing aspect of the MME process can be achieved using simple, stable (laser-free) and relatively inexpensive FDM desktop printers [20] as compared to established metal AM processes that employ high-energy laser beams to melt metal powders in a complex thermophysical process.

Currently, very little data have been published on systematic studies of MME. Documented studies $[21,22]$ implied that increasing metal fillers in the filaments will decrease the tensile strength and increase thermal conductivity of the composite materials. The dimensional changes and microstructure of MME-produced parts have recently been reported [23,24], together with comparisons of MME- and SLM-produced parts [25]. In the current study, representative parts are built from composite filaments that consist of polylactic acid (PLA) and copper ( $\mathrm{Cu}$ ), bronze (Br), stainless steel (SS), high carbon iron (HC), and aluminum (Al) powders. These parts are examined for mechanical properties to gauge their suitability for a wide range of engineering applications. The effects of printing parameters on mechanical and thermal properties are also investigated. For this study, mechanical characterization focused on Cu-PLA composite material, whereas thermal characterization focused on $\mathrm{Cu}$-, $\mathrm{Br}-$, SS-, HC-, and Al-PLA composite materials.

\section{Materials and Methods}

Filaments used in this study were purchased from the Virtual Foundry Company [26]. Bonding agents were used in the filaments to improve the strength between the polymer and metal phases. Weight percentage (\%) of copper, bronze, aluminum, high carbon iron, and stainless steel in filaments was $90,88,65,75$ and $85 \%$, respectively. Those containing copper, bronze and stainless steel were $3 \mathrm{~mm}$ in diameter while those containing high carbon iron and aluminum were $1.75 \mathrm{~mm}$ in diameter. The specimen fabrication steps are similar to those in the FDM process. Figure 1 shows the different steps of operation including modeling, file conversion, component slicing, filament warming, extrusion, sintering and post-processing.

Ultimaker S5 and Raise 3D pro2 3D printers were used to build test specimens. Ultimaker S5 is a Bowden-drive printer that utilizes $2.85 \mathrm{~mm}$ diameter filament. Raise 3D pro2, on the other hand, is a direct-drive printer that utilizes $1.75 \mathrm{~mm}$ diameter filament. The test specimens were printed with three different layer heights of $0.1,0.2$ and $0.3 \mathrm{~mm}$ and a printing speed of $10 \mathrm{~mm} / \mathrm{s}$. The printing temperature was increased to $230{ }^{\circ} \mathrm{C}$ to reduce the viscosity of PLA and increase the flow rate from the $0.4 \mathrm{~mm}$ extrusion nozzles. Table 1 shows the printing parameters used in this study.

An open box furnace (Lindberg/Blue M) is used for the sintering process. The sintering process is mainly divided into three parts: heating, holding at the sintering temperature, and cooling. In the experiment, the furnace temperature was increased to the sintering temperature at a uniform rate and then the furnace temperature was maintained for several hours to ensure that the metal particles were sintered and then polishing was performed after the part is cooled. 

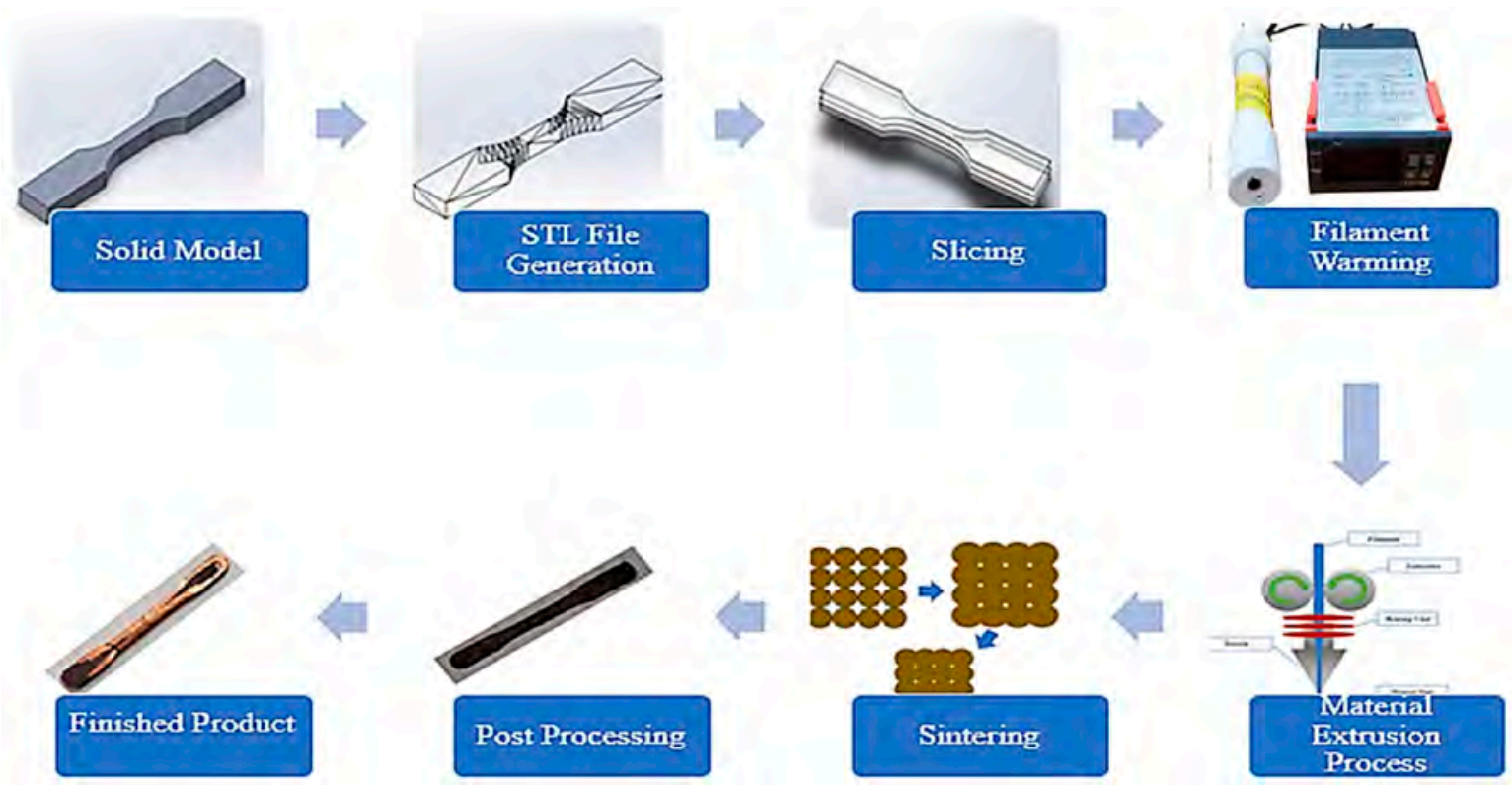

Figure 1. Process flow for low-cost metal additive manufacturing.

Table 1. Printing parameters for test specimens.

\begin{tabular}{cc}
\hline Parameter & Value \\
\hline Base material & PLA \\
Supports & No supports \\
Skirt line count & 3 \\
Infill density & $100 \%$ \\
Wall layers & Maximum \\
Printing temperature & $230^{\circ} \mathrm{C}$ \\
Build plate temperature & $60{ }^{\circ} \mathrm{C}$ \\
Printing speed & $10 \mathrm{~mm} / \mathrm{s}$ \\
\hline
\end{tabular}

Instron 5582 Universal Testing Machine was used to measure the tensile properties, i.e., ultimate tensile strength (UTS) and elastic modulus (E). The tests were conducted in accordance with the American Standard Test Model (ASTM) D638 requirements [27]. Because the specimen's dimension will reduce after sintering, during the printing process, the specimen's model's dimension was enlarged to a certain extent ensure that the reduced specimen's dimension is within the acceptable range. Microstructural morphology and build quality of the specimens were examined using an optical microscope model Nikon SMZ1500 (Tokyo, Japan). Thermogravimetric analysis (TGA) was conducted using a TA Instruments Q600 (New Castle, DE, USA) to measure the thermal decomposition temperature, thermal decomposition rate, true sintering temperature, and true weight percentage of the metal powders. Thermomechanical analysis (TMA) measured material deformation under the controlled thermal conditions. The test was conducted using TA instruments' TMA Q400 (New Castle, DE, USA) to study the coefficient of thermal expansion (CTE) of parts built by MME. Test specimens were cube-shaped with a side length of $7 \mathrm{~mm}$, fabricated with $0.1 \mathrm{~mm}$ layer height and contour infill pattern.

\section{Results and Discussion}

\subsection{Tensile Test}

The tensile properties of metal-PLA (MPLA) specimens were studied. The effects of extrusion parameters including layer thickness, and sintering temperature on tensile strength, elastic modulus and 
yield strength were also investigated. The test specimens examined were manufactured in accordance with ASTM D638 requirements.

The tensile test specimens from Cu-PLA filaments were built with layer thicknesses of 0.1 , 0.2 and $0.3 \mathrm{~mm}$ and sintered in Lindberg Blue M furnace (Waltham, MA, USA) at $1065^{\circ} \mathrm{C}$ to remove bonding agents and accelerate fusion between metal powder particles. The sintered specimens were manufactured as per the ASTM E8/E8M guidelines for tensile testing of powder metallurgy specimens. In terms of layer thickness, $0.1 \mathrm{~mm}$ is the minimum that can be extruded without nozzle abrasion and clogging, $0.2 \mathrm{~mm}$ is the machine's default, whereas $0.3 \mathrm{~mm}$ is commonly used based on nozzle size.

Table 2 compares data from the PLA, Cu-PLA, sintered Cu-PLA built in this study at $0.1 \mathrm{~mm}$ layer height with annealed $\mathrm{Cu}$, and other AM-produced $\mathrm{Cu}$. Although the tensile properties of PLA are higher than Cu-PLA, it is evident that sintering improved the latter immensely, with values comparable to annealed $\mathrm{Cu}[28]$ and exceeding those produced by AM. The data shown in Table 3 for sintered Cu-PLA imply a decrease in UTS and $E$ values as layer thickness increases. The stress-strain curves of the specimens are shown in Figure 2. The decline in mechanical properties in relation to increasing layer thickness could be attributed to the density of metal particles in the bead. Figure 3 shows a schematic of the effect of layer height on metal particles in the bead: as layer thickness reduces, the density of metals in the bead increases.

Table 2. Tensile properties of polylactic acid (PLA), Cu-PLA, sintered Cu-PLA, annealed Cu and additive manufacturing (AM)-produced $\mathrm{Cu}$.

\begin{tabular}{cccc}
\hline Material & UTS (MPa) & E (GPa) & Yield Stress (MPa) \\
\hline PLA & 66 & 3.5 & 48 \\
Cu-PLA & 22 & 1.4 & 18 \\
Cu-PLA sintered at 1065 ${ }^{\circ} \mathrm{C}$ & 188 & 101 & 55 \\
Annealed copper [23] & 210 & 110 & 33.3 \\
Direct SLM copper [29] & 149 & $\mathrm{NA}$ & $\mathrm{NA}$ \\
EBM copper [30] & 177 & $\mathrm{NA}$ & NA \\
Jet Binder copper [31] & 176.35 & $\mathrm{NA}$ & $\mathrm{NA}$ \\
\hline
\end{tabular}

Table 3. Tensile properties of sintered Cu-PLA specimens.

\begin{tabular}{cccc}
\hline Layer Height $(\mathbf{m m})$ & UTS (MPa) & E (GPa) & Yield Stress (MPa) \\
\hline 0.1 & 188 & 101 & 55 \\
0.2 & 166 & 39 & 36 \\
0.3 & 153 & 15 & 39 \\
\hline
\end{tabular}

The test results show that before sintering, the MPLA specimens have poor mechanical properties which limit any potential applications in this form. However, after being subjected to the sintering process, the mechanical properties of the MME Cu specimens are greatly improved. The mechanical properties of MME components are, however, lower than the more traditionally produced $\mathrm{Cu}$ parts, but still have higher mechanical properties compared with SLM- and Jet Binder-produced parts. Overall, it can be concluded that the MME specimens have mechanical properties within an acceptable tolerance/range of the standard engineering materials. It is apparent from the data that under certain conditions, this method can produce parts with mechanical properties close to those of other AM methods. This study uses an open box furnace. Therefore, the quality is not as good as the other AM methods. The quality of the parts is affected by some unavoidable factors, such as environmental humidity and oxygen content. Even if the same sintering setting is used, the mechanical property data will fluctuate due to changes in environmental conditions. 


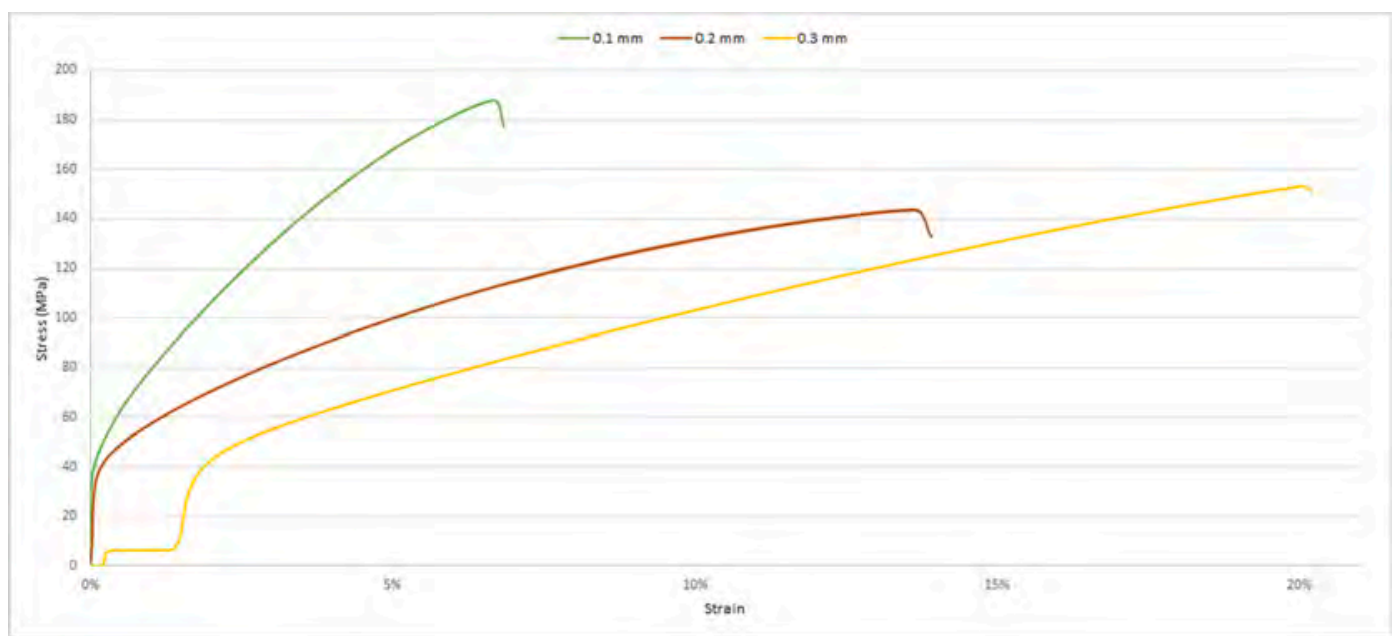

Figure 2. Stress-strain curves of sintered Cu-PLA built with different layer thickness.

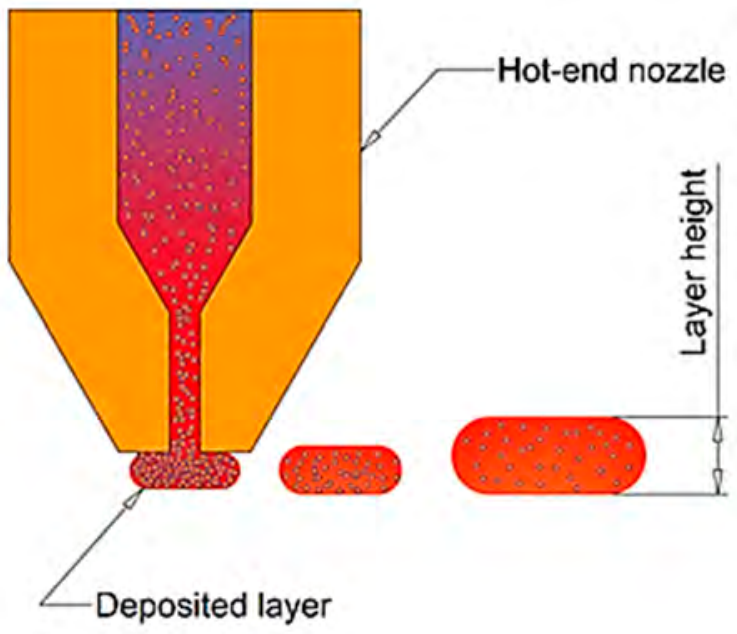

Figure 3. The effect of layer height variation on the metallic concentrations in deposited beads.

\subsection{Thermomechanical Analysis (TMA)}

Table 4 shows the CTE values of different specimens at distinct $\mathrm{x}, \mathrm{y}$, and $\mathrm{z}$ printing directions. As shown, metal inclusion reduces the CTE value of PLA, for which Cu-PLA recorded the lowest value as compared to other specimens. In addition, the CTE values for MPLAs are noted to be higher than traditional metals [28]. The purpose of furnace sintering is to employ the thermal expansion of the metal powder to push out the air in the structure to form a solid part. The analysis described herein was conducted in two different directions of the specimens: $x / y$ and $z$ axis. The CTE values obtained for MPLA specimens in the $z$ direction are higher than those in the $x / y$ direction. This is possibly due to the interface between layers. Because layers are perpendicular to the $z$ direction, an increase in the interface can cause expansion in the $z$ direction more than the $x / y$ direction.

Table 4. Coefficient of thermal expansion (CTE) of different filaments in the different extrusion directions.

\begin{tabular}{ccc}
\hline Material & \multicolumn{2}{c}{ Average CTE $\mathbf{~ m m} /(\mathbf{m ~ C})$} \\
\hline Direction & $x / y$ direction & $z$ direction \\
PLA & 0.07906 & 0.07983 \\
Cu-PLA & 0.05646 & 0.06311 \\
Al-PLA & 0.06927 & 0.07244 \\
HC-PLA & 0.06413 & 0.06980 \\
\hline
\end{tabular}




\subsection{Thermogravimetric Analysis (TGA)}

TGA is a thermal analysis method in which the mass of a sample is measured over time as the temperature increases at a defined rate. The tests for Cu-PLA, Br-PLA, SS-PLA, Al-PLA, and HC-PLA specimens were conducted to comply with ASTM E1131 [32] in the temperature range from room temperature to $500{ }^{\circ} \mathrm{C}$ and a constant heating rate of $10^{\circ} \mathrm{C} / \mathrm{min}$.

Each test was repeated $(2 \times)$ for reliability. Figure 4 shows the TGA curves of the five MPLA filaments examined. Cu-PLA recorded the highest thermal resistance followed by Br-PLA and SS-PLA. The lowest thermal resistance was recorded for Al-PLA. In this study, TGA provided detailed information on the degradation temperature and rate of decomposition of the materials within the temperature range of $250-400{ }^{\circ} \mathrm{C}$ at $2 \mathrm{~h}$. Each curve reveals the mass loss per degradation temperature from which the degradation rate was calculated: Cu-PLA and Al-PLA composite materials produced the lowest and highest degradation rate, respectively. MPLA decomposition temperature and residues are listed in Table 5. The decomposition temperatures are in the range of 230 to $400{ }^{\circ} \mathrm{C}$. All the curves plateaued out after $\approx 430^{\circ} \mathrm{C}$ until the end of the test. The horizontal part of the curve at high temperature confirms the residue (metal weight percentage) content. The data presented in Table 5 also corroborate the assertion that the thermal degradation temperature of PLA is higher than MPLAs [33].

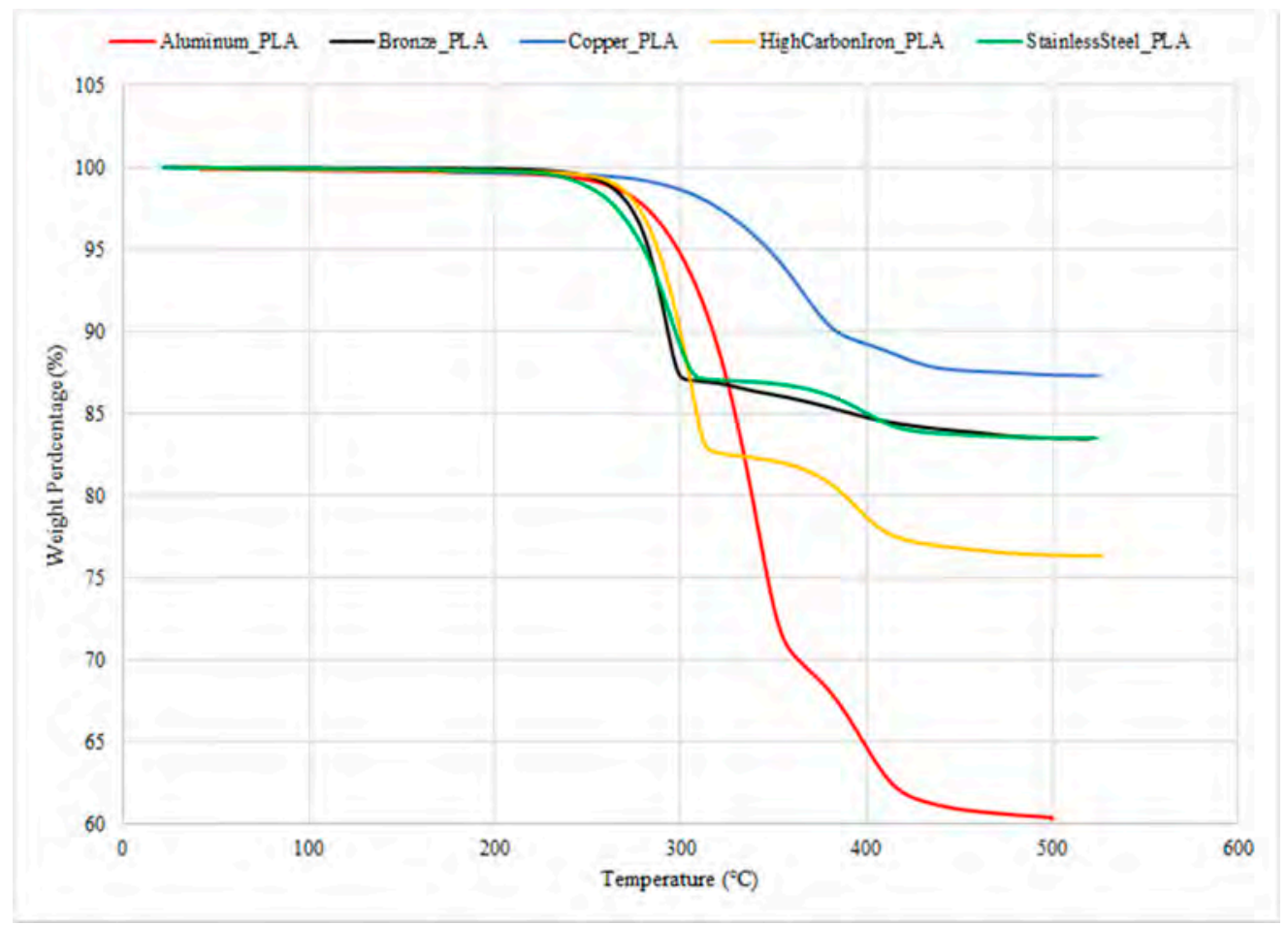

Figure 4. Thermogravimetric analysis (TGA) plot of metal-PLA (MPLA) specimens.

Table 5. Thermal degradation temperature of MPLAs and PLA.

\begin{tabular}{cccc}
\hline \multirow{2}{*}{ Material } & $\begin{array}{c}\text { Thermal Degradation Starting Temperature } \\
\left({ }^{\circ} \mathbf{C}\right)\end{array}$ & $\begin{array}{c}\text { Full Degradation Temperature } \\
\left({ }^{\circ} \mathbf{C}\right)\end{array}$ & Weight \% \\
\hline \multirow{2}{*}{ Cu-PLA } & 300.87 & 437.45 & 87.28 \\
& 293.73 & 399.49 & 85.51 \\
Br-PLA & 311.21 & 405.59 & 85.98 \\
& 242.52 & 439.45 & 83.60 \\
Al-PLA & 279.41 & 420.54 & 60.49 \\
& 271.37 & 420.65 & 60.45 \\
SS-PLA & 252.08 & 424.64 & 83.44 \\
& 227.33 & 408.27 & 83.80 \\
\hline
\end{tabular}


Table 5. Cont.

\begin{tabular}{cccc}
\hline \multirow{2}{*}{ Material } & $\begin{array}{c}\text { Thermal Degradation Starting Temperature } \\
\left({ }^{\circ} \mathbf{C}\right)\end{array}$ & $\begin{array}{c}\text { Full Degradation Temperature } \\
\left({ }^{\circ} \mathbf{C}\right)\end{array}$ & Weight \% \\
\hline \multirow{2}{*}{ HC-PLA } & 267.83 & 422.10 & 75.96 \\
PLA & 262.95 & 420.65 & 76.36 \\
\hline
\end{tabular}

\subsection{Microstructural Analysis}

The cross-sectional view of unsintered Cu-PLA specimens is shown in Figure 5. Two different phases for metal and polymer are visible with the bulk of the space filled by PLA. In the micrograph, the dark $\mathrm{Cu}$ particles (10 to $50 \mu \mathrm{m}$ ) are interspersed in the matrix.

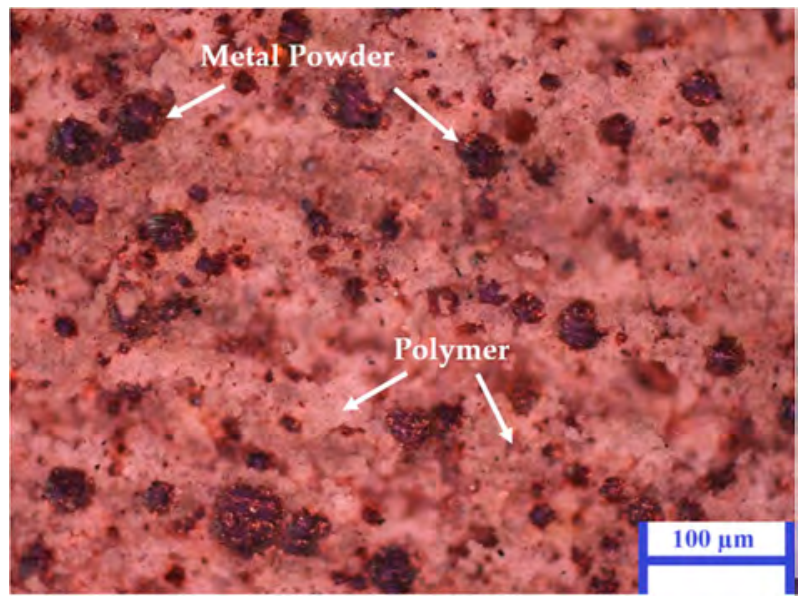

Figure 5. Cross-sectional views of Cu-PLA specimens.

The cross-sectional view of sintered $\mathrm{Cu}$ specimens is shown in Figure 6. The PLA content disappeared after sintering. The sintering process also influenced the void's area percentage. The average void area percentage changed from the initial $10.95 \%$ [24] to less than $1 \%$ with a $15{ }^{\circ} \mathrm{C}$ increase in the sintering temperature. The noticeable changes in Figures 5 and 6 demonstrate that after sintering, the voids in the structure reduced with a contemporaneous increase in tensile properties.

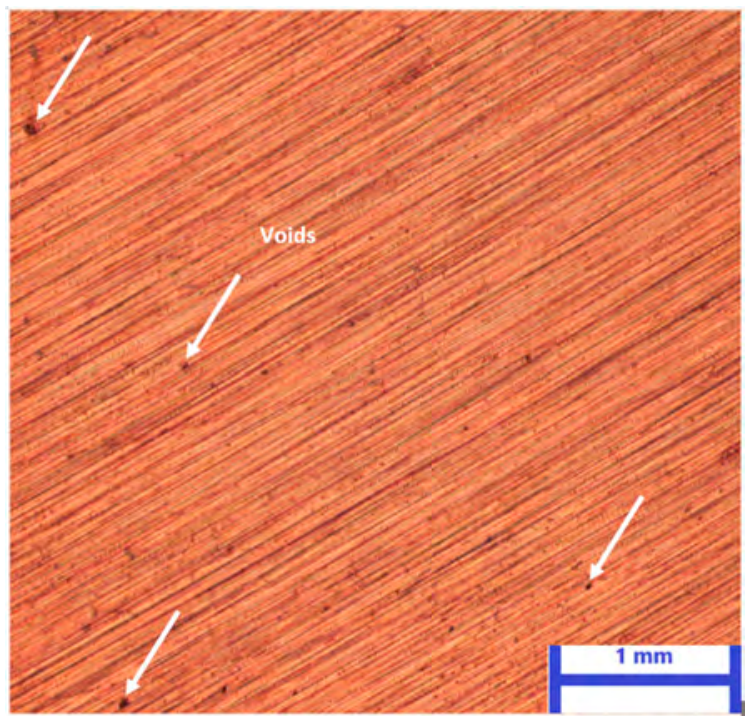

Figure 6. Cross-sectional views of sintered $\mathrm{Cu}$ specimens. 
Figure 7 shows the SEM images of sintered Cu's tensile test specimens' fracture with different printing layer thicknesses. The intra bead spaces (voids) decrease as the printed layer height decreases. The fractures of the test specimens are not smooth, indicating that they are ductile fractures.
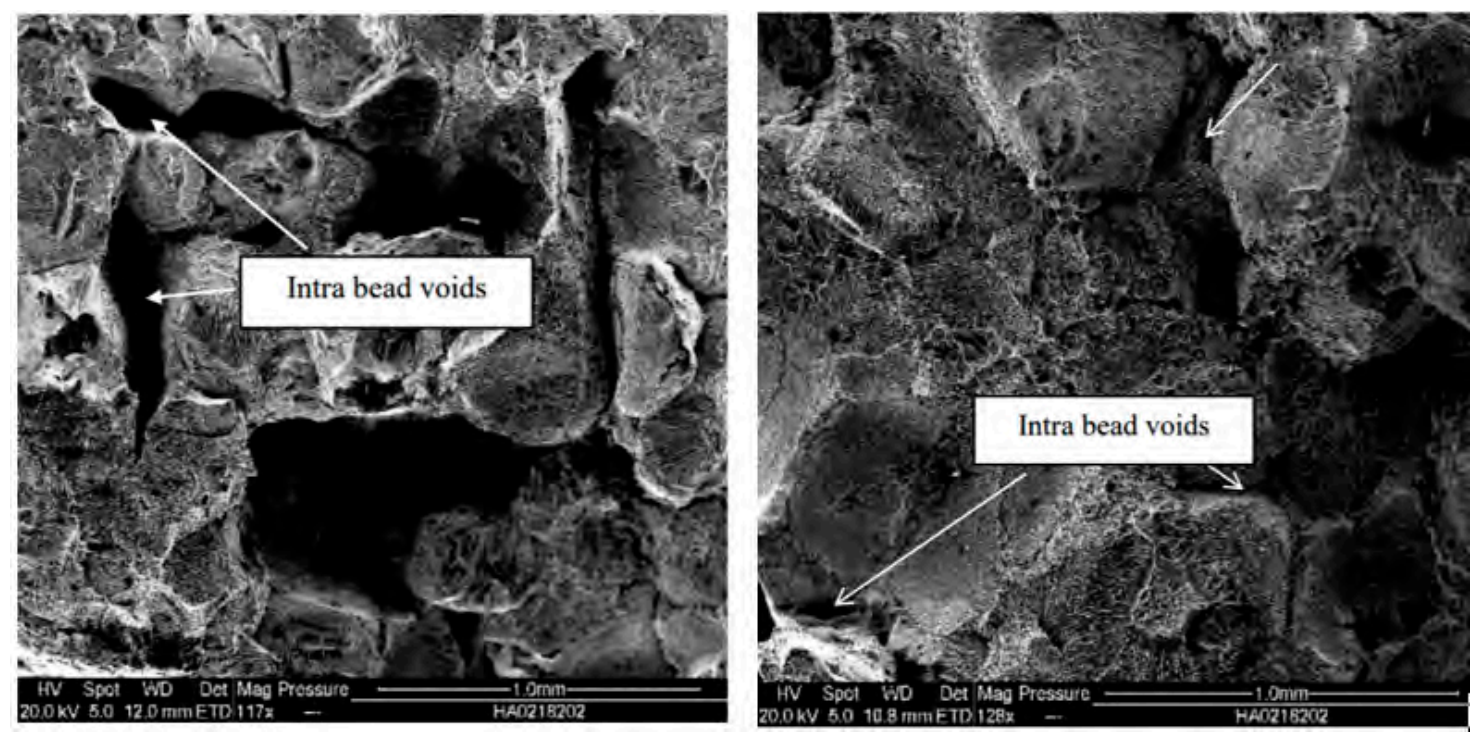

Figure 7. SEM image of sintered Cu's tensile test specimen's fracture with 0.3 (left) and $0.1 \mathrm{~mm}$ (right) lay thickness.

\subsection{Discussion}

It is evident from the above investigation that the infusion of $\mathrm{Cu}$ particles into PLA resulted in final parts with enhanced mechanical properties, comparable with those highlighted in Table 2. TGA and TMA analyses also show significant improvement in thermal properties of end use Cu as presented in Tables 4 and 5 .

During the study, the 3D printer and furnace worked at the maximum load and the power used during the printing process was about $0.5 \mathrm{kWh}$ per hour. The printing time for one cubic centimeter is about $0.2 \mathrm{~h}$. The furnace's power is $950 \mathrm{~W}$ and the sintering process can be finished in $11 \mathrm{~h}$ including rising temperature for $8 \mathrm{~h}$ and holding for $3 \mathrm{~h}$. Assuming the holding of temperature uses $50 \%$ power, the total power usage is about $9.2 \mathrm{kWh}$ per cubic centimeter. The energy consumption of the MME process is thus higher than other AM techniques [34]. The sintering process can, however, be optimized for a shorter time and lower energy consumption. The MME process does not need any closed environment with inert gases and powder collection system which eventually will reduce the cost of metal AM for individual users or small businesses. The initial capital of a metal 3D printer which ranges from hundreds of thousands to millions of dollars [17] generally makes it a non-viable investment for individuals or small organizations. The MME process, on the other hand, offers minimal initial (hardware) cost which can be as little as three thousand dollars. Hence, it is possible to make a functional part at a relatively low cost using the MME technology.

\section{Conclusions}

MME constitutes a relatively low-cost (in the context of equipment, materials, and maintenance) manufacturing option as compared to established metal AM processes. This research study thus presents a novel method that can be explored to fabricate affordable metallic parts. In this study, test specimens were prepared from composite materials using PLA (matrix) and $\mathrm{Cu}, \mathrm{Al}, \mathrm{Br}, \mathrm{HC}$, and SS (reinforcements) formulations. The furnace sintering process induced material shrinkage which ensured that the final parts exhibited improved mechanical properties. In TMA, the printing 
directions influenced the CTE of MPLAs. TGA confirmed that thermal degradation of the base polymer commenced at $\approx 250^{\circ} \mathrm{C}$.

Due to the COVID-19 pandemic situation, the mechanical tests for sintered specimens were not fully completed. Future work will aim to improve the physico-mechanical properties of the parts (e.g., reducing the voids created during sintering) and assess their suitability for different applications using for instance, fatigue and dynamic mechanical analysis to further characterize them. While the basic mechanical/thermal properties and sintering shrinkage ratios are gradually improved, a statistical model can be created for predicting dimensional changes of parts and their mechanical properties at different sintering temperatures. The current data fully support two conclusions. One is that the layer height is inversely proportional to Young's modulus; the other is that the sintering temperature is proportional to the ultimate tensile strength. However, the effect of layer height on the tensile strength needs to be explored more in order to draw further conclusions.

Author Contributions: Conceptualization, H.L., M.M.; methodology, M.M., H.L.; validation, H.L.; formal analysis, H.L., M.M., A.G.; investigation, H.L., M.M., I.F., K.T., A.G., S.H., F.A.-S., A.R.; resources, M.M., A.G.; data curation, H.L., M.M., S.H., Z.Z.; writing—original draft preparation, M.M., I.F., A.G.; writing-review and editing, M.M., I.F., K.T., Z.Z., S.H., F.A.-S., A.R.; supervision, I.F., K.T.; project administration, K.T. All authors have read and agreed to the published version of the manuscript.

Funding: This study has been funded through the National Science Foundation Award 1801120, Smart Manufacturing for America's Revolutionizing Technological Transformation.

Conflicts of Interest: The authors declare no conflict of interest.

\section{References}

1. Ventola, C.L. Medical applications for 3D printing: Current and projected uses. P T Peer-Rev. J. Formul. Manag. 2014, 39, 704-711.

2. Ngo, T.D.; Kashani, A.; Imbalzano, G.; Nguyen, K.T.Q.; Hui, D. Additive manufacturing (3D printing): A review of materials, methods, applications and challenges. Compos. Part B Eng. 2018, 143, 172-196. [CrossRef]

3. Bhavar, V.; Kattire, P.; Patil, V.; Khot, S.; Gujar, K.; Singh, R. A review on powder bed fusion technology of metal additive manufacturing. In Proceedings of the 4th International Conference and Exhibition on Additive Manufacturing Technologies-AM-2014, Banglore, India, 1-2 September 2014.

4. Buchanan, C.; Gardner, L. Metal 3D printing in construction: A review of methods, research, applications, opportunities and challenges. Eng. Struct. 2019, 180, 332-348. [CrossRef]

5. Mohammadizadeh, M.; Imeri, A.; Fidan, I.; Elkelany, M. 3D printed fiber reinforced polymer compositesStructural analysis. Compos. Part B Eng. 2019, 175, 107112. [CrossRef]

6. Nasirov, A.; Hasanov, S.; Fidan, I. Prediction of mechanical properties of fused deposition modeling made parts using multiscale modeling and classical laminate theory. In Proceedings of the 30th Annual International Solid Freeform Fabrication Symposium—An Additive Manufacturing Conference, Austin, TX, USA, 12-14 August 2019; pp. 1373-1382.

7. Chen, Z.; Li, Z.; Li, J.; Liu, C.; Lao, C.; Fu, Y.; Liu, C.; Li, Y.; Wang, P.; He, Y. 3D printing of ceramics: A review. J. Eur. Ceram. Soc. 2019, 39, 661-687. [CrossRef]

8. Mohammadizadeh, M.; Fidan, I.; Allen, M.; Imeri, A. Creep behavior analysis of additively manufactured fiber-reinforced components. Int. J. Adv. Manuf. Technol. 2018, 99, 1225-1234. [CrossRef]

9. Mohammadizadeh, M.; Fidan, I. Experimental Evaluation of Additively Manufactured Continuous Fiber Reinforced Nylon Composites. In Proceedings of the TMS 2020 149th Annual Meeting \& Exhibition Supplemental, San Diego, CA, USA, 23-27 February 2020.

10. Gupta, A.; Fidan, I.; Hasanov, S.; Nasirov, A. Processing, mechanical characterization, and micrography of 3D-printed short carbon fiber reinforced polycarbonate polymer matrix composite material. Int. J. Adv. Manuf. Technol. 2020, 107, 3185-3205. [CrossRef] 
11. Gupta, A.; Hasanov, S.; Fidan, I. Processing and characterization of 3D-printed polymer matrix composites reinforced with discontinuous fibers. In Proceedings of the 30th Annual International Solid Freeform Fabrication Symposium-An Additive Manufacturing Conference, Austin, TX, USA, 12-14 August 2019; pp. 1054-1066.

12. Frazier, W.E. Metal Additive Manufacturing: A Review. J. Mater. Eng. Perform. 2014, 23, 1917-1928. [CrossRef]

13. Fidan, I.; Imeri, A.; Gupta, A.; Hasanov, S.; Nasirov, A.; Elliott, A.; Nanami, N. The trends and challenges of fiber reinforced additive manufacturing. Int. J. Adv. Manuf. Technol. 2019, 102, 1801-1818. [CrossRef]

14. Misra, S.; Hussain, M.; Gupta, A.; Kumar, V.; Kumar, S.; Das, A.K. Fabrication and characteristic evaluation of direct metal laser sintered SiC particulate reinforced Ti6Al4V metal matrix composites. J. Laser Appl. 2019, 31. [CrossRef]

15. Gupta, A.; Hussain, M.; Misra, S.; Das, A.K.; Mandal, A. Processing and characterization of laser sintered hybrid B4C/cBN reinforced Ti-based metal matrix composite. Opt. Lasers Eng. 2018, 105, 159-172. [CrossRef]

16. Laureijs, R.E.; Roca, J.B.; Narra, S.P.; Montgomery, C.; Beuth, J.L.; Fuchs, E.R.H. Metal additive manufacturing: Cost competitive beyond low volumes. J. Manuf. Sci. Eng. 2017, 139, 1-9. [CrossRef]

17. Greguric, L. All3DP. Available online: https://all3dp.com/2/how-much-does-a-metal-3d-printer-cost/ (accessed on 24 July 2020).

18. Lewandowski, J.J.; Seifi, M. Metal Additive Manufacturing: A Review of Mechanical Properties. Annu. Rev. Mater. Res. 2016, 46, 151-186. [CrossRef]

19. Richter, A. MarrweHackers. Available online: https://www.matterhackers.com/articles/how-to-succeed-wh en-3D-printing-with-metal-PLA (accessed on 25 July 2020).

20. Riecker, S.; Clouse, J.; Studnitzky, T.; Andersen, O.; Kieback, B. Fused Deposition Modeling-Opportunities for cheap metal AM. In Proceedings of the World PM2016 Congress \& Exhibition, Hamburg, Germany, 9-13 October 2016.

21. Hwang, S.; Reyes, E.I.; Moon, K.S.; Rumpf, R.C.; Kim, N.S. Thermo-mechanical Characterization of Metal/Polymer Composite Filaments and Printing Parameter Study for Fused Deposition Modeling in the 3D Printing Process. J. Electron. Mater. 2015, 44, 771-777. [CrossRef]

22. Masood, S.H.; Song, W.Q. Thermal characteristics of a new metal/polymer material for FDM rapid prototyping process. Assem. Autom. 2005, 25, 309-315. [CrossRef]

23. Terry, S.; Fidan, I.; Tantawi, K. Dimensional Analysis of Metal Powder Infused Filament_Low Cost Metal 3D Printing. In Proceedings of the Solid Freeform Fabrication 2019: Proceedings of the 30th Annual International Solid Freeform Fabrication Symposium-An Additive Manufacturing Conference, Austin, TX, USA, 12-14 August 2019.

24. Terry, S.M. Innovating the Fused Filament Fabrication Process Metal Powder Polylactic Acid Printing; ProQuest Dissertations Publishing, ProQuest LLC: Ann Arbor, MI, USA, 2019.

25. Liu, B.; Wang, Y.; Lin, Z.; Zhang, T. Creating metal parts by fused deposition modeling and sintering. Mater. Lett. 2020, 263, 127252. [CrossRef]

26. The Virtual Foundry. Available online: https://www.thevirtualfoundry.com (accessed on 25 July 2020).

27. ASTM D638-14. Standard Test Method for Tensile Properties of Plastics; ASTM International: West Conshohocken, PA, USA, 2014; Available online: https://www.astm.org/Standards/D638 (accessed on 25 July 2020).

28. MatWeb. Available online: http://www.matweb.com/search/DataSheet.aspx?MatGUID=9aebe83845c04c1db 5126fada6f76f7e (accessed on 25 July 2020).

29. Lykov, P.A.; Safonov, E.V.; Akhmedianov, A.M. Selective Laser Melting of Copper. Mater. Sci. Forum 2016, 843, 284-288. [CrossRef]

30. Guschlbauer, R.; Momeni, S.; Osmanlic, F.; Körner, C. Process development of $99.95 \%$ pure copper processed via selective electron beam melting and its mechanical and physical properties. Mater. Charact. 2018, 143, 163-170. [CrossRef]

31. Yegyan Kumar, A.; Bai, Y.; Eklund, A.; Williams, C.B. The effects of Hot Isostatic Pressing on parts fabricated by binder jetting additive manufacturing. Addit. Manuf. 2018, 24, 115-124. [CrossRef]

32. ASTM E1131-08. Standard Test Method for Compositional Analysis by Thermogravimetry; ASTM International: West Conshohocken, PA, USA, 2015; Available online: https://www.astm.org/Standards/D638 (accessed on 25 July 2020). 
33. Ma, P.; Jiang, L.; Ye, T.; Dong, W.; Chen, M. Melt Free-Radical Grafting of Maleic Anhydride onto Biodegradable Poly(lactic acid) by Using Styrene as a Comonomer. Polymers 2014, 6, 1528-1543. [CrossRef]

34. Alex, H. DigitalAlloys. Available online: https://www.digitalalloys.com/blog/joule-printing-vs-wire-ded/ (accessed on 26 July 2020). 